\title{
Elevated Inflammatory Status and Increased Risk of Chronic Disease in Chronological Aging: Inflamm-aging or Inflamm-inactivity?
}

\author{
Michael G. Flynn ${ }^{1,2,}$, , Melissa M. Markofski ${ }^{3}$, Andres E. Carrillo ${ }^{4,5}$ \\ ${ }^{1}$ HCA South Atlantic Division, Charleston, SC 29492, USA \\ ${ }^{2}$ College of Charleston, Charleston, SC 29424, USA \\ ${ }^{3}$ University of Houston, Department of Health and Human Performance, Houston, TX 77204, USA \\ ${ }^{4}$ Department of Exercise Science, Chatham University, Pittsburgh, PA 15232, USA \\ ${ }^{5}$ FAME Laboratory, Department of Exercise Science, University of Thessaly, Trikala, Greece
}

[Received January 6, 2018; Revised March 22, 2018; Accepted March 26, 2018]

\begin{abstract}
Age-associated hyper-inflammation or "inflamm-aging" has been linked to the development of chronic diseases and characterized as an unavoidable aspect of aging. However, the inflamm-aging model does not adequately address the potential anti-inflammatory effects of exercise training and the potential for exercise to ameliorate several age-related diseases. In this brief review, we introduce a new paradigm-inflamminactivity - that describes a potent counter-measure to age-associated inflammatory illness.
\end{abstract}

Key words: inflammation, exercise, physical activity, immune system, gerontology

Inflammation, an ancient mechanism for protection against injury and infection, is highly conserved and a critical aspect of our host defense [1]. Nevertheless, poorly regulated innate immunity and inflammation contribute to the development or maintenance of chronic disease, such that biomarkers of low-level chronic inflammation are now being recognized as important predictors of disease risk. Cardiovascular disease, type 2 diabetes, and osteoporosis, to name three, are known to be exacerbated by a poorly regulated innate immune system.

In 2000, Franceschi et al. [2] coined the term "inflamm-aging" to describe the elevated chronic inflammation commonly observed in older persons and the coincident increase in co-morbidities. It was suggested that inflamm-aging is " .... an inescapable result of the long lasting exposure to acute and chronic infections and the consequent lifelong antigenic burden..." [3]. It is necessary to acknowledge that the introduction of this neologism [4] was a significant event that altered how we view the development of age-related disease. In subsequent writings Franceschi's group recognized that hyper-inflammation alone was not sufficient to increase age-related disease and proposed that a "second hit" was required, such as a genetic pre-disposition to disease or an overly aggressive inflammatory response. The latter point and the ability of exercise training to significantly reduce inflammation, and reduce the likelihood of the "second hit," is the foundation of our paper.

Although it seems counter-intuitive, there is an exercise training-induced anti-inflammatory effect, observed in both younger and older subjects [5-8]. There is some disagreement in the literature, yet an increasing volume of evidence points to the ability of regular, planned exercise, or a high level of physical activity, to

*Correspondence should be addressed to: Dr. Michael G. Flynn, HCA South Atlantic Division, Charleston, SC 29492, USA. Email: mike.flynn@hcahealthcare.com.

Copyright: () 2018 Flynn MG et al. This is an open-access article distributed under the terms of the Creative Commons Attribution License, which permits unrestricted use, distribution, and reproduction in any medium, provided the original author and source are credited. 
reduce the inflammatory burden [9-11]. Gleeson et al. published a review in 2011 that comprehensively described the general mechanisms by which exercise exerts its anti-inflammatory actions, including a reduction in toll-like receptor (TLR) expression on monocytes and phenotypic switching of macrophages within adipose tissue, just to name a few [12]. We found that 10-12 weeks of moderate exercise lowered inflammatory biomarkers and monocyte TLR4 expression of previously sedentary, elderly subjects to similar levels as young subjects. These accumulating findings lead us to argue that the hyperinflammatory state in older subjects is strongly linked to physical activity, is reversible, and may not be an inescapable part of the aging process [6]. In this brief review, we will present evidence in support of a newlycoined phrase 'inflamm-inactivity' along with which we propose that a substantial proportion of the so-called ageassociated hyper-inflammatory state is linked to a sedentary lifestyle and its subsequent impact on body fat accumulation.

\section{Inflamm-Aging}

In 2000, Franceschi et al. [2] melded the concomitant occurrence of an increased risk of age-associated chronic diseases and the age-associated increase in proinflammatory cytokines into a new paradigm - inflammaging. Among the key tenets of their paradigm is that inflammatory cytokines played a key role in the aging process, influenced disease risk, and reduced life span. In their initial model, Franceschi et al. used the network theory of aging $[2,13,14]$ to identify a cellular defense network that included oxygen free-radical scavenging, DNA damage repair, heat shock response, and UV-stress recovery. These systems, they contended, work together to protect the cell from aging [13]. They extended the network theory of aging by suggesting that disruption of the protective network is combined with a progressive pro-inflammatory surge, which they called inflamm-aging and argued that it is concomitant with increased disease risk, morbidity, and mortality. Their logic flows from a patient's obligatory, lifelong exposure to, and defense against, antigens and a shift in the functional capacities of the immune system as we age - an antagonistic pleiotropy of debilitating cytokines and aberrant responses. That is, inflammatory responses that prevent infection in early life, contribute to disease in later life. In this early work, Franceschi et al. (2001) implicated the innate immune system as a primary culprit with a special focus on the macrophage and its propensity to produce inflammatory cytokines. In subsequent work, Franceschi's group [3] included an anti-inflammaging paradigm. Specifically, that cortisol, transforming growth factor (TGF) beta, and other anti-inflammatory proteins work in opposition to the hyper-inflammatory state, increase longevity, and lead to successful aging. Giunta [15] discussed the antiinflammaging paradigm and speculated that the hyperactivation of the hypothalmic-pituitary-adrenal axis with aging - and the resultant hyper-cortisolism-likely accelerates the slide into frailty through its negative influence on muscle, bone, adipose tissue, exercise capacity, metabolism, mood, and cognitive function. Thus, anti-inflammaging as defined by Giunta [15], is not an effective counter-measure, but instead contributes to a progressive decline in function that can lead to frailty in inactive older people.

Franceschi et al. $[3,16]$ listed and described several chronic diseases, such as cardiovascular disease and type 2 diabetes that could be linked to the late-life cytokine surge. However, the potential influence of physical activity on both inflammation and chronic diseases is conspicuous by its absence in the early work by this group. In 2014, Franceschi's group acknowledged that exercise may be an effective counter measure for inflamm-aging [17]. Minciullo et al. [18] argued that if inflamm-aging helps us to explain and understand aging, anti-inflammaging is vital to longevity. Thus, the primary purpose of our paper is to highlight the potential of regular, planned exercise or high levels of physical or obligate activity to attenuate the hyper-inflammatory state commonly associated with aging.

Franceschi [3] used an evolutionary-based systems argument to make his group's case. That is, the immune system, shaped by evolution, performs quite well in young people, but is inefficient and hyper-stimulated when asked to respond to the "evolutionary unpredicted" exposure over the succeeding decades [3]. Booth et al. [19] opined that the human genome evolved to be active, to find food, and to store energy efficiently in times of plenty so that it would be available in times of insufficiency. They argued that modern man's ready access to food in large quantities and enforced inactivity result in a sedentary phenotype that leads to impaired metabolism, dysfunction, and chronic disease. Our task is to reconcile these elegant hypotheses and attempt to determine what proportion of inflamm-aging is attributable to the sedentariness that increases as we age-inflamm-inactivity.

Most of the chronic diseases associated with inflamm-aging are known to be positively influenced by physical activity. As an example, a recent work by Pinti et al. [20] details the link between inflamm-aging and the danger signal created by circulating mitochondrial DNA. The impact of sedentary versus an active lifestyle on mitochondrial function is well documented and provides an example of the multitude of positive effects exerted by regular exercise participation. In addition, we see 
evidence in the literature, and in our own work, that later life increases in inflammation may not be inescapable, but rather a result of low physical activity and/or high levels of body fat $[6,8,10,21-28]$. It is not our intent to impugn the important work and intriguing hypothesis set forth by Franceschi and colleagues; rather, we hope to have physical activity considered as part of the inflamm-aging model. Are physically active individuals able to delay or prevent inflamm-aging? Does physical activity or planned exercise exert its beneficial effect on chronic disease by blunting inflammation? Is inflamm-aging escapable?

\section{Potential peril of excluding physical activity from the inflamm-aging model}

We argue that leaving the exercise training influences out of the inflamm-aging model is at best incomplete and at worst attributing the hyper-inflammatory state to the influence of aging per se and not allowing for the substantial impact of exercise training on inflammation that we and others have reported in older and younger subjects [6, 23, 24, 29-31]. In fact, when considering inflammatory biomarkers, there are frequent examples in the literature of physically active older adults being indistinguishable from physically active young people $[6$, 29].

Franceschi et al. [3] described four potential protective mechanisms: molecular, cellular, systemic, and organismal. At the molecular level are DNA repair mechanisms, heat shock proteins, protein and organelle turnover, and anti-oxidant enzymes. At the cellular level, Franceschi and coworkers [3] list apoptosis, phagocytosis, cell senescence, and progenitor cell replacement of dead or damaged cells. At the systemic level are the immune, inflammatory, stress and neuroendocrine responses, and at the organismal level are behavioral/avoidance responses that could reduce damage or danger. Franceschi et al. [3] suggested that these responses, collectively, contribute to the survival and longevity of an organism; however, a strong case can be made to show a significant influence of exercise training, and associated lifestyle behaviors, in each of these four areas.

The largely positive effects of exercise training on chronic disease, physical, and mental health have been clearly documented. In addition, the potential for exercise training to influence function at the organismal, cellular, molecular and signaling levels is clear. Exercise training lowers inflammation [6-8, 24], increases heat shock protein transcription/protection [32], refines processes of immune function and apoptosis [32-36], improves antioxidant capacity [37], responsiveness to vaccine [38], wound healing [39], cell signaling [32, 40] the neuroendocrine response [41], skeletal muscle function
[42], retards cellular senescence [33], and enhances cognitive function $[43,44]$. Thus, the broad influence of exercise training on physiological systems and functions is suggestive of a significant influence on the aging process. While the present paper is focused on the potential anti-inflammatory influences of exercise training, the related influences of exercise training on damage mechanisms cannot be overlooked.

\section{Age-Associated Changes in Physical Activity}

Participation in regular physical activity exerts antiinflammatory effects that counter the age-associated increase in pro-inflammatory biomarkers [23]. Habitual physical activity, however, is highly variable throughout the course of a lifetime [45, 46]. Could age-associated variations in inflammatory biomarkers reflect ageassociated variations in physical activity? Several researchers provided support for the contention that the frequency and intensity of physical activity declines with advancing age [45-48].

Despite the general acceptance of the importance of regular physical activity, physical inactivity is widespread. For example, less than half of adult men and women in the United States perform the recommended amounts of daily exercise, with levels of inactivity showing a steady rise with advancing age [45]. Xue et al. [48] 2012 followed physical activity patterns of 433 older women $(70-79$ years at baseline) for 12 years. The physical inactivity prevalence at baseline (48\%) increased to $62 \%$ by the end of the study. Using accelerometer data, Troiano and colleagues reported an age-related decline in physical activity with $<5 \%$ of individuals over 60 years of age meeting the physical activity recommendations [49]. These age-associated physical activity declines have important clinical implications that may be related to increased inflammation and chronic disease risk.

Along with the decline in physical activity participation, there appears to be an age-associated shift in the type/intensity of physical activity [47]. DiPietro et al. 2001 [47] described an age-associated decline in highintensity physical activity participation that paralleled an increasing prevalence of physical inactivity. Recently, In and So [50] reported that only $1.2 \%$ of $\sim 1400$ older individuals ( $>65$ years) participated in high-intensity exercise, compared to $7.4 \%$ of adults (19-64 years) and $11.5 \%$ of adolescents ( $<18$ years). Conversely, $17.7 \%$ of elderly individuals participated in low-intensity exercise, compared to $8.2 \%$ of adults, and $2.5 \%$ of adolescents [50]. An age-associated decline in exercise intensity reflects the type of activities reported in different age groups. Specifically, common activities of younger, physically active individuals include higher intensity activities such 
as running, team sports, weight lifting, and aerobics [47]. The most prevalent activities reported among those $>65$ years of age are lower intensity, such as walking, gardening, golf using a cart, and home exercises [47, 51].

Exercise intensity differences within a physically active population are relevant when considering the antiinflammatory effects of exercise, as demonstrated by the National Health and Nutrition Examination Survey III (1988 - 1994). Specifically, in 13,748 adult participants within the United States, the age-adjusted odds ratios for elevated CRP concentrations were 0.78, 0.59, and 0.30, for light, moderate, and vigorously active participants, respectively [52]. In contrast, Onambele-Pearson et al. 2010 [53] had 39 older volunteers ( 73 years of age) complete either a low- or high-intensity 12-week resistance training intervention. The high-intensity group experienced significant strength gains compared to the low-intensity group, but a significant decrease in TNFa was reported only in the low-intensity group [53]. It is possible that a variety of exercise intensities may be beneficial in stimulating a potent anti-inflammatory effect.

Regardless of intensity, participation in physical activities provides health benefits that include antiinflammatory actions. The age-associated decline in overall physical activity participation is of major concern for the progression of inflammation among older populations. The inflammatory consequences of a sedentary lifestyle will be described in a later section; but based on the research described above, age-associated changes in physical activity support the nascent notions proposed by our inflamm-inactivity paradigm.

\section{Inflammation and Physical Activity Status}

Biomarkers of inflammation are consistently linked to chronic disease risk. For example, high levels of IL-6 and $\mathrm{TNF} \alpha$ are associated with an increased risk of cardiovascular disease [54]. Additionally, high CRP and IL-6 concentrations are associated with type 2 diabetes and impaired glucose tolerance [55]. Consistent elevation of these biomarkers is associated with aging and an increase in chronic disease risk, but there are also modifiable characteristics associated with a lower proinflammatory biomarker concentration and disease risk. Two of these modifiable factors are physical activity and body composition.

\section{Inflammation and inactivity}

Across the lifespan, physical activity is associated with a decreased and increased concentration of inflammatory and anti-inflammatory biomarkers, respectively. Several researchers reported a relationship between physical activity and inflammation [52, 56-61]. Physically active young and older adults had significantly lower concentrations of circulating pro-inflammatory biomarkers compared to young and older physically inactive adults $[6,23]$. Moreover, 12-weeks of exercise training significantly decreased these biomarkers, obfuscating differences between physically active subjects and the previously physically inactive subjects [6]. In addition to exercise decreasing inflammatory biomarkers, highly conditioned older adults have elevated concentrations of anti-inflammatory biomarkers such as IL-10 [62].

In light of the suggestion that inflammation is an inescapable part of aging, research on children and adolescents builds a case for inactivity being responsible for elevated inflammatory biomarkers. For example, CRP is inversely related to physical fitness in children [59]. This relationship is also present in middle-aged [52] and older [61] adults. The inverse relationship between activity and inflammation is present in children as young as ten years old [63]. Finally, there is a similar correlation between body weight and inflammatory biomarkers that may partially explain higher inflammation in inactive people. Irrespective of age, overweight and obese individuals have increased inflammation [63-66].

\section{Physiological Changes Resulting from Inactivity}

A cross-sectional comparison of physically inactive versus physically active subjects yields several significant differences such as body weight or fat mass differences. Other differences, such as metabolism and insulin signaling, are not as consistent. We believe this ambiguity is due to the interrelatedness of body composition, inflammation, and metabolism.

\section{Body Composition}

Participation in regular exercise aids in body weight maintenance $[67,68]$. For example, in studies comparing age-matched physically inactive and physically active adults, physically active subjects had significantly lower body weight $[6,24,69]$. The body weight difference can be considered a potential covariate. However, since inactivity likely contributed to a significant increase in body weight, it is difficult to separate the individual effects of inactivity and increased body weight. Regardless, increased body weight and body fat are consistently linked to higher inflammation $[65,70,71]$.

An example of body composition having a systemic effect is exerted by the most abundant adipokine, adiponectin. Adiponectin has anti-inflammatory actions, 
including stimulating anti-inflammatory cytokine production and inhibiting NF- $\kappa \mathrm{B}[72,73]$. In addition, adiponectin increases insulin secretion $[74,75]$ and may enhance fatty acid $\beta$-oxidation [75]. Although adiponectin is produced by adipocytes, more adipocytes do not equate to more adiponectin. Obese people have lower plasma adiponectin than non-obese people [76]. In an apparently paracrine action [72], the pro-inflammatory cytokines TNF $\alpha$ and IL-6, produced by adipocytes, inhibit adiponectin expression. Changes in adiponectin may be independent of weight change, as exercise training increases plasma adiponectin in older adults [77]. Collectively, this demonstrates a complex relationship between adiposity and inflammation and underscores the difficulty in separating inflammation resulting from ageassociated body weight gain or physical inactivity.

\section{Insulin Resistance/Glucose Metabolism}

Physical inactivity is consistently linked to elevated blood glucose and insulin resistance [56, 78, 79]. For example, five days of bedrest significantly increased fasting blood glucose, insulin, total cholesterol, and HOMA-IR (50\%) in young adults [80], making bedrest an effective model to study inactivity-induced metabolic changes. Increases in fasting blood glucose and insulin resistance are important because these two variables are a component of metabolic syndrome - a condition that is also characterized by elevated inflammation [81, 82]. Furthermore, older adults are at an increased risk of developing metabolic syndrome and type 2 diabetes [83], but this risk is lower in physically active older adults [84] - suggesting that inactivity is a greater risk factor than age. Taken together, physically inactive individuals have higher amounts of inflammation, and this inflammation directly contributes to insulin resistance and type 2 diabetes $[85,86]$.

\section{Does Exercise Exert Anti-Inflammatory Actions?}

As described above, high levels of physical activity, including aerobic exercise and resistance training, are linked to anti-inflammatory effects. Although there are numerous benefits to exercise, most of the research involving physical activity in relation to chronic, low grade inflammation resulted in an anti-inflammatory effect [87, 88]. Several mechanisms are involved in reducing chronic inflammation; with inflammation lowering effects of exercise training on the muscle, endothelial cells, and immune cells reported [89].

Conversely, researchers have reported no change in inflammation biomarkers as a result of regular exercise training [90, 91]. CRP levels were unchanged after 421 overweight or obese females with elevated systolic blood pressure were separated into either a control or one of three exercise groups for 6 months [90]. In another study involving overweight or obese patients $(n=52)$ there were no differences in CRP levels between a control group of three-months exercise training group [91]. It is possible that a focus on additional inflammatory biomarkers may have yielded a different result; however, it's clear that not all researchers have found an anti-inflammatory response to exercise. It is also possible the subjects' overweight or obese status could have influenced the ability of exercise to exert an anti-inflammatory effect.

\section{Inflamm-Aging and The Physical Activity Habits of Centenarians}

Centenarians provide a unique opportunity for further study and discovery of clues that may help counter inflamm-aging. For example, centenarians express an unusual combination of both pro- and anti-inflammatory biomarkers [3]. This cytokine balance may be a critical component of successful aging among this unique population. Specifically, centenarians appear to counteract the progression of inflamm-aging with potent anti-inflammatory activity that is not necessarily evident in the general population [3]. To delay inflamm-aging and promote successful aging, a number of anti-inflammaging strategies have been proposed, such as the development of safe, anti-inflammatory medications. Physical activity, however, exerts anti-inflammatory effects in both young and older individuals [23]. Physical activity participation is an important component of lifestyle that works in combination with genetics to dictate aging trajectories. Vigorous physical activity among an older population has been associated with a lower prevalence of multimorbidities that may develop, at least in part, due to inflammatory processes [92]. Among a population of 878 centenarians studied in Chongqing, China, $64 \%$ had the physical abilities to live and function autonomously. Adequate physical exercise was described as a key lifestyle factor for this successfully aged population [93]. In another study, regular physical exercise was described among 1907 Japanese centenarians as a critical determinant of autonomy and successful aging [94]. The anti-inflammatory effects of physical activity and its importance as a component in establishing autonomous living suggests that regular physical activity may contribute to establishing a healthy balance of pro- and anti-inflammatory biomarkers that may delay the progression of inflamm-aging and its related morbidities in this unique population. 


\section{Inflamm-Inactivity}

New developments, in this case the impact of physical activity on inflamm-aging, require a new perspective. In this brief review, we introduced the term 'inflamminactivity' that represents a proportion of the ageassociated hyper-inflammatory state that occurs due to a sedentary lifestyle. Introducing inflamm-inactivity into the aging vernacular will allow for a clearer understanding of the development of a hyper-inflammatory state - an understanding that hyper-inflammation is multi-factorial and modifiable, with application of planned exercise or increased physical activity. Expanding the concepts that represent factors influencing the complex nature of ageassociated inflammation can lead to more sophisticated prevention strategies. Specifically, an awareness of the impact a sedentary lifestyle has on aging (i.e., inflamminactivity) provides a new perspective that can lead to refined anti-inflammatory interventions strategically modified across the lifespan.

\section{Summary and Conclusions}

We presented a new paradigm-inflamm-inactivity - to account for the significant proportion of the age-related hyper-inflammatory state due to a sedentary lifestyle. We reported that physical activity participation and intensity decline with advancing age; that this decline is likely a contributing factor in increasing inflammatory biomarkers; and that there are a host of diseases and metabolic disorders linked to the hyper-inflammatory state, also a key tenet of the inflamm-aging paradigm. These paradigms diverge at the contention that the hyperinflammatory state is an inescapable consequence of advancing age. Exercise training and increased physical activity are consistently shown to be an effective countermeasure against hyper-inflammation. Additional research is required to evaluate the durability of the exercise counter-measure, the specific effects on aging and longevity, and nuanced conditions under which the antiinflammatory effects of exercise are permitted. It should not be overlooked that exercise has positive influences on many of the chronic diseases identified in the inflammaging paradigm. It will take some time before the consequences of aging per se on inflammation and illness can be partitioned from the consequences of a sedentary lifestyle. We have provided evidence in this document that shows exercise training-induced, short-term reversal of elevated inflammatory biomarkers, receptors and cellular responses. It is not known how durable and sustainable these effects are but the age-associated "inflammation curve" is certainly shifted to the right in those who exercise regularly.

\section{Acknowledgements}

This research was supported (in whole or in part) by HCA and/or an HCA-affiliated entity. The views expressed in this publication represent those of the author(s) and do not necessarily represent the official views of HCA or any of its affiliated entities.

\section{References}

[1] Ley K. 2001. Physiology of inflammation. Oxford ; New York: Oxford University Press. xii, 546 p. pp.

[2] Franceschi C, Bonafè M, Valensin S, Olivieri F, De Luca M, Ottaviani E, et al. (2000). Inflamm-aging. An evolutionary perspective on immunosenescence. Ann N Y Acad Sci, 908:244-254.

[3] Franceschi C, Capri M, Monti D, Giunta S, Olivieri F, Sevini $\mathrm{F}$, et al. (2007). Inflammaging and antiinflammaging: a systemic perspective on aging and longevity emerged from studies in humans. Mech Ageing Dev, 128:92-105.

[4] Waters DJ (2017). On cultivating an attitude of precision with language: An uncommon prescription for conditioning creative excellence in scientific discovery and education. TEXT, special issue 40 Making it new: Finding contemporary meanings for creativity. Retrieved from www.textjournal.com.au/speciss/issue40/Waters.pdf.

[5] Timmerman KL, Flynn MG, Coen PM, Markofski MM, Pence BD (2008). Exercise training-induced lowering of inflammatory (CD14+CD16+) monocytes: a role in the anti-inflammatory influence of exercise? J Leukoc Biol, 84:1271-1278.

[6] Stewart LK, Flynn MG, Campbell WW, Craig BA, Robinson JP, McFarlin BK, et al. (2005). Influence of exercise training and age on $\mathrm{CD} 14+$ cell-surface expression of toll-like receptor 2 and 4. Brain Behav Immun, 19:389-397.

[7] Kohut M, McCann D, Russell D, Konopka D, Cunnick J, Franke W, et al. (2006). Aerobic exercise, but not flexibility/resistance exercise, reduces serum IL-18, CRP, and IL-6 independent of beta-blockers, BMI, and psychosocial factors in older adults. Brain Behav Immun, 20:201-209.

[8] Markofski MM, Flynn MG, Carrillo AE, Armstrong CL, Campbell WW, Sedlock DA (2014). Resistance exercise training-induced decrease in circulating inflammatory CD14+CD16+ monocyte percentage without weight loss in older adults. Eur J Appl Physiol, 114:1737-1748.

[9] Hammonds TL, Gathright EC, Goldstein CM, Penn MS, Hughes JW (2016). Effects of exercise on creactive protein in healthy patients and in patients with heart disease: A meta-analysis. Heart Lung, 45:273282.

[10] Fedewa MV, Hathaway ED, Ward-Ritacco CL (2017). Effect of exercise training on $\mathrm{C}$ reactive protein: a systematic review and meta-analysis of randomised 
and non-randomised controlled trials. Br J Sports Med, 51:670-676.

[11] Allen J, Sun Y, Woods JA (2015). Exercise and the Regulation of Inflammatory Responses. Prog Mol Biol Transl Sci, 135:337-354.

[12] Gleeson M, Bishop NC, Stensel DJ, Lindley MR, Mastana SS, Nimmo MA (2011). The antiinflammatory effects of exercise: mechanisms and implications for the prevention and treatment of disease. Nat Rev Immunol, 11:607-615.

[13] Franceschi C, Valensin S, Bonafè M, Paolisso G, Yashin AI, Monti D, et al. (2000). The network and the remodeling theories of aging: historical background and new perspectives. Exp Gerontol, 35:879-896.

[14] Franceschi C (1989). Cell proliferation, cell death and aging. Aging Clin Exp Res, 1:3-13.

[15] Giunta S, Sergio G (2008). Exploring the complex relations between inflammation and aging (inflammaging): anti-inflamm-aging remodelling of inflammaging, from robustness to frailty. Inflamm Res, 57:558-563.

[16] Franceschi C (2007). Inflammaging as a major characteristic of old people: can it be prevented or cured? Nutr Rev, 65:S173-176.

[17] Franceschi C, Campisi J (2014). Chronic inflammation (inflammaging) and its potential contribution to age-associated diseases. J Gerontol A Biol Sci Med Sci, 69 Suppl 1:S4-9.

[18] Minciullo PL, Catalano A, Mandraffino G, Casciaro M, Crucitti A, Maltese G, et al. (2016). Inflammaging and Anti-Inflammaging: The Role of Cytokines in Extreme Longevity. Arch Immunol Ther Exp (Warsz), 64:111-126.

[19] Booth FW, Chakravarthy MV, Spangenburg EE (2002). Exercise and gene expression: physiological regulation of the human genome through physical activity. J Physiol, 543:399-411.

[20] Pinti M, Cevenini E, Nasi M, De Biasi S, Salvioli S, Monti D, et al. (2014). Circulating mitochondrial DNA increases with age and is a familiar trait: Implications for "inflamm-aging". Eur J Immunol, 44:1552-1562.

[21] Flynn MG, McFarlin BK, Phillips MD, Stewart LK, Timmerman KL (2003). Toll-like receptor 4 and CD14 mRNA expression are lower in resistive exercisetrained elderly women. J Appl Physiol, 95:1833-1842.

[22] McFarlin BK, Flynn MG, Campbell WW, Stewart LK, Timmerman KL (2004). TLR4 is lower in resistancetrained older women and related to inflammatory cytokines. Med Sci Sports Exerc, 36:1876-1883.

[23] McFarlin BK, Flynn MG, Campbell WW, Craig BA, Robinson JP, Stewart LK, et al. (2006). Physical activity status, but not age, influences inflammatory biomarkers and toll-like receptor 4. J Gerontol A Biol Sci Med Sci, 61:388-393.

[24] Timmerman KL, Flynn MG, Coen PM, Markofski MM, Pence BD (2008). Exercise training-induced lowering of inflammatory (CD14+CD16+) monocytes: a role in the anti-inflammatory influence of exercise?
Journal of Leukocyte Biology, 84:1271-1278.

[25] Bruun JM, Helge JW, Richelsen B, Stallknecht B (2006). Diet and exercise reduce low-grade inflammation and macrophage infiltration in adipose tissue but not in skeletal muscle in severely obese subjects. Am J Physiol Endocrinol Metab, 290:E961967.

[26] Fischer C, Berntsen A, Perstrup L, Eskildsen P, Pedersen B (2007). Plasma levels of interleukin-6 and C-reactive protein are associated with physical inactivity independent of obesity. Scand J Med Sci Sports, 17:580-587.

[27] Lambert C, Wright N, Finck B, Villareal D (2008). Exercise but not diet-induced weight loss decreases skeletal muscle inflammatory gene expression in frail obese elderly persons. J Appl Physiol, 105:473-478.

[28] Marfella R, Esposito K, Siniscalchi M, Cacciapuoti F, Giugliano F, Labriola D, et al. (2004). Effect of weight loss on cardiac synchronization and proinflammatory cytokines in premenopausal obese women. Diabetes Care, 27:47-52.

[29] Greiwe JS, Cheng B, Rubin DC, Yarasheski KE, Semenkovich CF (2001). Resistance exercise decreases skeletal muscle tumor necrosis factor alpha in frail elderly humans. Faseb J, 15:475-482.

[30] Gielen S, Adams V, Mobius-Winkler S, Linke A, Erbs $\mathrm{S}$, Yu J, et al. (2003). Anti-inflammatory effects of exercise training in the skeletal muscle of patients with chronic heart failure. J Am Coll Cardiol, 42:861-868.

[31] Adamopoulos S, Parissis J, Kroupis C, Georgiadis M, Karatzas D, Karavolias G, et al. (2001). Physical training reduces peripheral markers of inflammation in patients with chronic heart failure. Eur Heart J, 22:791-797.

[32] Liebelt B, Papapetrou P, Ali A, Guo M, Ji X, Peng C, et al. (2010). Exercise preconditioning reduces neuronal apoptosis in stroke by up-regulating heat shock protein-70 (heat shock protein-72) and extracellular-signal-regulated-kinase $1 / 2$. Neuroscience, 166:1091-1100.

[33] Werner C, Fürster T, Widmann T, Pöss J, Roggia C, Hanhoun M, et al. (2009). Physical exercise prevents cellular senescence in circulating leukocytes and in the vessel wall. Circulation, 120:2438-2447.

[34] Soufi FG, Farajnia S, Aslanabadi N, Ahmadiasl N, Alipour M, Doustar Y, et al. (2008). Long-term exercise training affects age-induced changes in HSP70 and apoptosis in rat heart. Gen Physiol Biophys, 27:263-270.

[35] Simpson RJ (2011). Aging, persistent viral infections, and immunosenescence: can exercise "make space"? Exerc Sport Sci Rev, 39:23-33.

[36] Silva LC, de Araujo AL, Fernandes JR, Matias Mde S, Silva PR, Duarte AJ, et al. (2016). Moderate and intense exercise lifestyles attenuate the effects of aging on telomere length and the survival and composition of T cell subpopulations. Age (Dordr), 38:24.

[37] Rinaldi B, Corbi G, Boccuti S, Filippelli W, Rengo G, Leosco D, et al. (2006). Exercise training affects age- 
induced changes in SOD and heat shock protein expression in rat heart. Exp Gerontol, 41:764-770.

[38] Kohut ML, Cooper MM, Nickolaus MS, Russell DR, Cunnick JE (2002). Exercise and psychosocial factors modulate immunity to influenza vaccine in elderly individuals. J Gerontol A Biol Sci Med Sci, 57:M557562.

[39] Keylock K, Vieira V, Wallig M, DiPietro L, Schrementi M, Woods J (2008). Exercise accelerates cutaneous wound healing and decreases wound inflammation in aged mice. Am J Physiol Regul Integr Comp Physiol, 294:R179-184.

[40] Olesen J, Kiilerich K, Pilegaard H (2010). PGClalpha-mediated adaptations in skeletal muscle. Pflugers Arch, 460:153-162.

[41] Reyna SM, Ghosh S, Tantiwong P, Meka CS, Eagan P, Jenkinson CP, et al. (2008). Elevated toll-like receptor 4 expression and signaling in muscle from insulinresistant subjects. Diabetes, 57:2595-2602.

[42] Fiatarone MA, O'Neill EF, Ryan ND, Clements KM, Solares GR, Nelson ME, et al. (1994). Exercise training and nutritional supplementation for physical frailty in very elderly people. N Engl J Med, 330:17691775.

[43] Chirles TJ, Reiter K, Weiss LR, Alfini AJ, Nielson KA, Smith JC (2017). Exercise Training and Functional Connectivity Changes in Mild Cognitive Impairment and Healthy Elders. J Alzheimers Dis, 57:845-856.

[44] Aquino G, Iuliano E, di Cagno A, Vardaro A, Fiorilli $\mathrm{G}$, Moffa S, et al. (2016). Effects of combined training vs aerobic training on cognitive functions in COPD: a randomized controlled trial. Int $\mathrm{J}$ Chron Obstruct Pulmon Dis, 11:711-718.

[45] Macera CA, Ham SA, Yore MM, Jones DA, Ainsworth BE, Kimsey CD, et al. (2005). Prevalence of physical activity in the United States: Behavioral Risk Factor Surveillance System, 2001. Prev Chronic Dis, 2:A17.

[46] Caspersen C, Merritt R (1995). Physical activity trends among 26 states, 1986-1990. Med Sci Sports Exerc, 27:713-720.

[47] DiPietro L (2001). Physical activity in aging: changes in patterns and their relationship to health and function. J Gerontol A Biol Sci Med Sci, 56 Spec No 2:13-22.

[48] Xue QL, Bandeen-Roche K, Mielenz TJ, Seplaki CL, Szanton SL, Thorpe RJ, et al. (2012). Patterns of 12year change in physical activity levels in communitydwelling older women: can modest levels of physical activity help older women live longer? Am J Epidemiol, 176:534-543.

[49] Troiano RP, Berrigan D, Dodd KW, Mâsse LC, Tilert T, McDowell M (2008). Physical activity in the United States measured by accelerometer. Med Sci Sports Exerc, 40:181-188.

[50] In S, So WY (2015). Toward a customized program to promote physical activity by analyzing exercise types in adolescent, adult, and elderly koreans. J Hum Kinet, 45:261-267.

[51] Ashe MC, Miller WC, Eng JJ, Noreau L, Team
[60] Jankord R, Jemiolo B (2004). Influence of physical activity on serum IL-6 and IL-10 levels in healthy older men. Med Sci Sports Exerc, 36:960-964.

[61] Geffken DF, Cushman M, Burke GL, Polak JF, Sakkinen PA, Tracy RP (2001). Association between physical activity and markers of inflammation in a healthy elderly population. Am J Epidemiol, 153:242250 .

[62] Minuzzi LG, Rama L, Bishop NC, Rosado F, Martinho A, Paiva A, et al. (2017). Lifelong training improves anti-inflammatory environment and maintains the number of regulatory $\mathrm{T}$ cells in masters athletes. Eur $\mathrm{J}$ Appl Physiol, 117:1131-1140.

[63] Cook DG, Mendall MA, Whincup PH, Carey IM, Ballam L, Morris JE, et al. (2000). C-reactive protein concentration in children: relationship to adiposity and other cardiovascular risk factors. Atherosclerosis, 149:139-150.

[64] Ghanim H, Aljada A, Hofmeyer D, Syed T, Mohanty P, Dandona P (2004). Circulating mononuclear cells in the obese are in a proinflammatory state. Circulation, 110:1564-1571.

[65] Visser M, Bouter LM, McQuillan GM, Wener MH, 
Harris TB (1999). Elevated C-Reactive Protein Levels in Overweight and Obese Adults. JAMA, 282:21312135.

[66] Visser M, Bouter LM, McQuillan GM, Wener MH, Harris TB (2001). Low-Grade Systemic Inflammation in Overweight Children. Pediatrics, 107:e13-.

[67] King AC, Frey-Hewitt B, Dreon DM, Wood PD (1989). Diet vs exercise in weight maintenance. The effects of minimal intervention strategies on long-term outcomes in men. Arch Intern Med, 149:2741-2746.

[68] Ewbank PP, Darga LL, Lucas CP (1995). Physical activity as a predictor of weight maintenance in previously obese subjects. Obes Res, 3:257-263.

[69] Coen PM, Flynn MG, Markofski MM, Pence BD, Hannemann RE (2010). Adding exercise to rosuvastatin treatment influence on $\mathrm{C}$-reactive protein, monocyte toll-like receptor 4 expression, and inflammatory monocyte $(\mathrm{CD} 14+\mathrm{CD} 16+)$ population. Metabolism-Clinical and Experimental, 59:1775-1783.

[70] Fontana L, Eagon JC, Trujillo ME, Scherer PE, Klein S (2007). Visceral Fat Adipokine Secretion Is Associated With Systemic Inflammation in Obese Humans. Diabetes, 56:1010-1013.

[71] Ellulu MS, Khaza'ai H, Rahmat A, Patimah I, Abed Y (2016). Obesity can predict and promote systemic inflammation in healthy adults. Int J Cardiol, 215:318324.

[72] Wolf AM, Wolf D, Rumpold H, Enrich B, Tilg H (2004). Adiponectin induces the anti-inflammatory cytokines IL-10 and IL-1RA in human leukocytes. Biochem Biophys Res Commun, 323:630-635.

[73] Yamaguchi N, Argueta JG, Masuhiro Y, Kagishita M, Nonaka K, Saito T, et al. (2005). Adiponectin inhibits Toll-like receptor family-induced signaling. FEBS Lett.

[74] Yamauchi T, Kamon J, Waki H, Terauchi Y, Kubota N, Hara K, et al. (2001). The fat-derived hormone adiponectin reverses insulin resistance associated with both lipoatrophy and obesity. Nat Med, 7:941-946.

[75] Patané G, Caporarello N, Marchetti P, Parrino C, Sudano D, Marselli L, et al. (2013). Adiponectin increases glucose-induced insulin secretion through the activation of lipid oxidation. Acta Diabetol, 50:851-857.

[76] Arita Y, Kihara S, Ouchi N, Takahashi M, Maeda K, Miyagawa J, et al. (1999). Paradoxical decrease of an adipose-specific protein, adiponectin, in obesity. Biochem Biophys Res Commun, 257:79-83.

[77] Markofski MM, Carrillo AE, Timmerman KL, Jennings K, Coen PM, Pence BD, et al. (2014). Exercise Training Modifies Ghrelin and Adiponectin Concentrations and Is Related to Inflammation in Older Adults. Journals of Gerontology Series aBiological Sciences and Medical Sciences, 69:675681.

[78] Jago R, Wedderkopp N, Kristensen PL, Moller NC, Andersen LB, Cooper AR, et al. (2008). Six-year change in youth physical activity and effect on fasting insulin and HOMA-IR. Am J Prev Med, 35:554-560.
[79]

O'Leary VB, Marchetti CM, Krishnan RK, Stetzer BP, Gonzalez F, Kirwan JP (2006). Exercise-induced reversal of insulin resistance in obese elderly is associated with reduced visceral fat. J Appl Physiol, 100:1584-1589.

[80] Hamburg NM, McMackin CJ, Huang AL, Shenouda SM, Widlansky ME, Schulz E, et al. (2007). Physical inactivity rapidly induces insulin resistance and microvascular dysfunction in healthy volunteers. Arterioscler Thromb Vasc Biol, 27:2650-2656.

[81] Picchi A, Gao X, Belmadani S, Potter BJ, Focardi M, Chilian WM, et al. (2006). Tumor necrosis factoralpha induces endothelial dysfunction in the prediabetic metabolic syndrome. Circ Res, 99:69-77.

[82] Mirhafez SR, Pasdar A, Avan A, Esmaily H, Moezzi A, Mohebati M, et al. (2015). Cytokine and growth factor profiling in patients with the metabolic syndrome. $\mathrm{Br}$ J Nutr, 113:1911-1919.

[83] Kraja AT, Borecki IB, North K, Tang W, Myers RH, Hopkins PN, et al. (2006). Longitudinal and age trends of metabolic syndrome and its risk factors: the Family Heart Study. Nutr Metab (Lond), 3:41.

[84] Bassuk SS, Manson JE (2005). Epidemiological evidence for the role of physical activity in reducing risk of type 2 diabetes and cardiovascular disease. $\mathrm{J}$ Appl Physiol (1985), 99:1193-1204.

[85] Odegaard JI, Chawla A (2013). Pleiotropic actions of insulin resistance and inflammation in metabolic homeostasis. Science, 339:172-177.

[86] Karstoft K, Pedersen BK (2016). Exercise and type 2 diabetes: focus on metabolism and inflammation. Immunol Cell Biol, 94:146-150.

[87] Gondim OS, de Camargo VT, Gutierrez FA, Martins PF, Passos ME, Momesso CM, et al. (2015). Benefits of Regular Exercise on Inflammatory and Cardiovascular Risk Markers in Normal Weight, Overweight and Obese Adults. PLoS One, 10:e0140596.

[88] Iyalomhe O, Chen Y, Allard J, Ntekim O, Johnson S, Bond V, et al. (2015). A standardized randomized 6month aerobic exercise-training down-regulated proinflammatory genes, but up-regulated antiinflammatory, neuron survival and axon growthrelated genes. Exp Gerontol, 69:159-169.

[89] You T, Arsenis NC, Disanzo BL, Lamonte MJ (2013). Effects of exercise training on chronic inflammation in obesity : current evidence and potential mechanisms. Sports Med, 43:243-256.

[90] Stewart LK, Earnest CP, Blair SN, Church TS (2010). Effects of different doses of physical activity on Creactive protein among women. Med Sci Sports Exerc, 42:701-707.

[91] Kadoglou NP, Fotiadis G, Athanasiadou Z, Vitta I, Lampropoulos S, Vrabas IS (2012). The effects of resistance training on ApoB/ApoA-I ratio, Lp(a) and inflammatory markers in patients with type 2 diabetes. Endocrine, 42:561-569.

[92] Dhalwani NN, O'Donovan G, Zaccardi F, Hamer M, Yates T, Davies M, et al. (2016). Long terms trends of 
multimorbidity and association with physical activity in older English population. Int J Behav Nutr Phys Act, 13:8.

[93] Li Y, Bai Y, Tao QL, Zeng H, Han LL, Luo MY, et al. (2014). Lifestyle of Chinese centenarians and their key beneficial factors in Chongqing, China. Asia Pac J
Clin Nutr, 23:309-314.

[94] Ozaki A, Uchiyama M, Tagaya H, Ohida T, Ogihara R (2007). The Japanese Centenarian Study: autonomy was associated with health practices as well as physical status. J Am Geriatr Soc, 55:95-101. 